\title{
Seroprevalence and trend of Helicobacter pylori infection in Gondar University Hospital among dyspeptic patients, Gondar, North West Ethiopia
}

\author{
Biniam Mathewos ${ }^{1 *}$, Beyene Moges ${ }^{1}$ and Mulat Dagnew ${ }^{2}$
}

\begin{abstract}
Background: The growing attention given to H. pylori is not surprising since this pathogen colonizes more than at least half of the world's inhabitants. In Ethiopia particularly in Gondar, there is no current study conducted about seroprevalence and trend of the prevalence of $\mathrm{H}$. pylori. Therefore the aim of this study was to determine the seroprevalence and its trend of the H. pylori in three consecutive years in North Gondar, North West Ethiopia.

Findings: Retrospective study was conducted using data collected from log book of serology laboratory of Gondar University Hospital. We collected data from January 2009 to December 2011 and 1388 subjects were included whose data were registered completely.

Among all of the study subjects, 912 (65.7\%) were found to be seropositive. The prevalence in male was 449/679 (66.1\%) and in females it was 463/709 (65.3\%). The prevalence of H.pylori infection was significantly higher (77.0\%) in patients whose age is greater than 60 years and the lowest positive age group was between 0-20 in which only $59.1 \%$ were positive $\left(X^{2}=14.15, p=0.0146\right)$. The seroprevalence was $86.5 \%$ in 2009 and it decreased to $51.8 \%$ in 2010 . But the seroprevalence increased to $61.3 \%$ in 2011.
\end{abstract}

Conclusion: This study showed high seroprevalence of $\mathrm{H}$.pylori among the dyspeptic patients in GUH. The trend of the seroprevalence was varied from year to year in the three consecutive years. In general it showed that the seroprevalence has started increasing.

Keywords: H. pylori, Dyspeptic patients, Seroprevalence

\section{Background}

H. pylori is cause of most chronic bacterial infection in the world. As to different seroepidemiologic studies, $50 \%$ of adults in the developed countries and $90 \%$ of adults in the developing countries were seropositive for H. pylori [1]. This currently discovered organism is a spiral shaped gram negative bacilli that is oxidase, catalase and urease positive and grows slowly in culture [2]. The ecological niche of $H$. pylori is the stomach where the organism establishes long term colonization of the gastric mucosa [3].

The bacteria have been implicated for acid peptic disease and today it is regarded as essential factor and also

\footnotetext{
* Correspondence: fikrbinny@gmail.com

${ }^{1}$ Department of Immunology and Molecular Biology, School of Biomedical and Laboratory Sciences, College of Medicine and Health Sciences, University of Gondar, Gondar, Ethiopia

Full list of author information is available at the end of the article
}

causative agent of gastritis and peptic ulcer disease [4]. Additionally, the organism is classified as a class 1 carcinogen because of its causal relationship to gastric adenocarcinoma, one of the world's deadliest cancers $[5,6]$.

The growing attention given to H. pylori by academicians and clinicians is not surprising since this pathogen colonizes more than at least half of the world's inhabitants [7] with an evident geographical variation in its epidemiology. This geographical variation is believed to be largely socio economical, age gender, genetic predisposition and sanitation. In Ethiopia particularly in Gondar, there is no current study conducted about the seroprevalence and its trend in consecutive years of $H$. pylori infection. Therefore the aim of this study was to determine the seroprevalence and its trend in three consecutive years of the H. pylori infection in three consecutive years in North Gondar, North West Ethiopia.

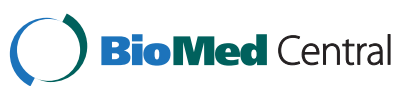

(c) 2013 Mathewos et al.; licensee BioMed Central Ltd. This is an Open Access article distributed under the terms of the Creative Commons Attribution License (http://creativecommons.org/licenses/by/2.0), which permits unrestricted use, distribution, and reproduction in any medium, provided the original work is properly cited. 


\section{Findings}

\section{Research hypothesis}

We hypothesized that the seroprevalence of $H$. pylori is greater than $50 \%$ in the study area and the trend of the seroprevalence will show increasing year from year.

\section{Methods}

Study design and area

Restrospective study was conducted using data from serology log book. We took data from the log book starting from January 2009 to December 2011. We collected data of all patients who were suspected for $H$. pylori infection and who visited the GUH serology laboratory for H. pylori test. The hospital is found in Gondar town which is located in the North Gondar Zone of the Amhara region. GUH is one of the oldest health institutions in Ethiopia. The hospital provides different inpatient and outpatient services to more than 5 million people in northwest Ethiopia. The study was conducted the in serology laboratory of the hospital.

\section{Sample size and sampling techniques}

A total of 1388 subjects whose data was completely registered were included in the study.

\section{Data collection, processing and analysis}

Data was collected from log book of the serology laboratory in the hospital. Completeness of the data collected was checked. The frequency distribution of variables was done. The data was entered and analyzed using SPSS version 20 .

\section{Laboratory method}

The hospital laboratory generated the data by a serological method of detecting the antibodies for Helicobacter pylori from serum or plasma. Anti $H$. pylori antibodies of all isotypes (IgG, IgM, IgA) against H. pylori were detected by one step rapid test device (dBest $H$. pylori test strip, Ameritech USA). Appearance of color band on the device on both test line and control line was interpreted as positive but if it is only on the control line as negative result.

\section{Ethical consideration}

We obtained approval from Research and Ethics Committee of School of Biomedical and Laboratory Sciences. Official letter were also obtained from the diagnostic director of the hospital to collect the data. All data obtained has been kept confidential.

\section{Results}

Socio demographic characteristics of the study subjects Among the total study subjects, 679 (48.9\%) were males and $709(51.1 \%)$ were females. The mean age of the study subjects was 28 year and the range was from 95 to
2 years. A majority of patients 466/1388 (33.6\%) were young adults in the age range of 21-30 years compared to the other age groups. The lowest patient number (5.3\%) was obtained in patients older than 60 years of age (Table 1). The male to female ratio was 1:1.04.

\section{Seroprevalence of $H$. pylori infection among different age and gender}

Among all the study subjects, 912 (65.7\%) were found to be seropositive and the remaining 476 (34.3\%) were found seronegative for $H$. pylori. The prevalence in male was $449 / 679(66.1 \%)$ and in females it was $463 / 709$ (65.3\%). The prevalence of $H$. pylori infection was significantly higher $(77.0 \%)$ in patients whose age is greater than 60 years and the lowest seropositivity (59.1\%) was obtained in the age group of $0-20\left(\mathrm{x}^{2}=14.15, \mathrm{p}=0.746\right)$ (Table 1).

Trend of the seroprevalence of Helicobacter pylori among three consecutive years

The trend of the seroprevalence of $H$. pylori infection among the dyspeptic patients from 2009 to 2011 was that the seroprevalence was $86.5 \%$ in the year of 2009 and it decreased to $51.8 \%$ in 2010 . However, the seroprevalence increased again to $61.3 \%$ in the year of 2011 (Figure 1). This trend showed decrement of the seroprevalence temporarily but it started increments after that. This alarm designing appropriate prevention and control strategies is mandatory.

\section{Discussion}

The overall prevalence of $H$. pylori infection in the present study was $65.7 \%$ which showed that it was lower than earlier report of prevalence of $85.6 \%$ for $H$. pylori in the study area [8]. The low prevalence in the present study may be attributed to improvement in environmental sanitation.

Table 1 Seroprevalence of Helicobactor pylori among dyspeptic patients in Gondar University Hospital, from January 2009 to December 2011

\begin{tabular}{lccccc}
\hline Variables & $\mathbf{N}(\%)$ & $\begin{array}{c}\text { Pos } \\
\mathbf{N}(\%)\end{array}$ & $\begin{array}{c}\text { Neg } \\
\mathbf{N}(\%)\end{array}$ & $\mathbf{X}^{\mathbf{2}}$ & P-value \\
\hline Age in year & & & & & \\
$0-20$ & $252(18.2)$ & $149(59.1)$ & $103(40.9)$ & & \\
$21-30$ & $466(33.6)$ & $307(65.9)$ & $159(34.1)$ & & \\
$31-40$ & $256(18.4)$ & $161(62.8)$ & $95(37.1)$ & 14.15 & 0.0146 \\
$41-50$ & $227(16.4)$ & $154(67.9)$ & $73(32.1)$ & & \\
$51-60$ & $113(8.1)$ & $84(74.3)$ & $29(25.7)$ & & \\
$>60$ & $74(5.3)$ & $57(77)$ & $17(23)$ & & \\
Sex & & & & & \\
Male & $679(48.9)$ & $449(66.1)$ & $230(33.9)$ & 0.1 & 0.746 \\
Female & $709(51.1)$ & $463(65.3)$ & $246(34.7)$ & & \\
\hline
\end{tabular}




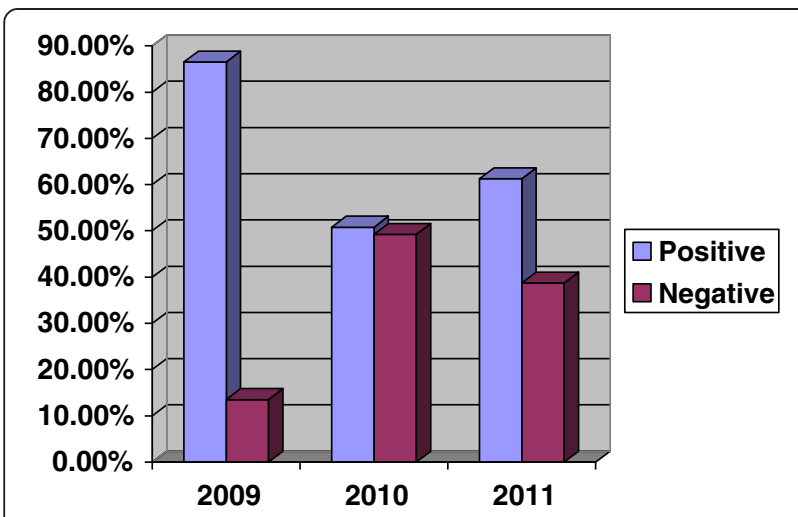

Figure 1 Trend of seroprevalence of Helicobacter pylori among dyspeptic patients from 2009-2011 in Gondar University Hospital, North West Ethiopia.

When we compare it with other studies it is similar with study conducted in Bahir Dar Felege Hiwot referral hospital (near to Gondar town) with prevalence of (49-70\%) [9] and this similarity might be due to the similarity of the two population in socio economic factors, environmental sanitation and their feeding habits.

The present study showed lesser seroprevalence than study conducted in Addis Ababa, capital city of Ethiopia, reported a seroprevalance of $89 \%$ [10]. This might be due to elimination of $H$. pylori infection as a result of other antibiotic treatments in occasion of concomitant diseases, such as giardiasis, amoebiasis, and respiratory diseases, etc., as these diseases are reported to be more prevalent in the study area [11].

When we compare the seroprevalence with studies conducted in some other countries like, Iran Hong Kong, United States, Canada (in Ontario) and Kuwait the seroprevalence reported was 43\% [12], 42.8\% [13], 9.4\% [14], 23.1\% [15] and 49.7\% [16] respectively which all showed lower than the present study. This might be best explained by association between $H$. pylori infection and socioeconomic status since in countries with low socioeconomic status, there is low level of hygiene and environmental sanitation and also in adequate provision of safe water which are known predisposing factors for the infection.

The association between sex and seropositivity in the present study showed that, H. pylori infection has no statistically significant association with sex. Similarly in another studies even though there were varying reports of higher prevalence of $H$. pylori infection in either males or females there is no significance association between the seropositivity and sex $[8,9]$.

There was a strong association between age and the disease in this study. Among the six age groups, the lowest $(58.8 \%)$ and the highest (77.0\%) seroprevalence rate were found between the age group of 31-40 years and greater than 60 years age respectively. This result showed that higher frequency of infection was found among older patients. The age related increase in the seroprevalence of the disease in this study was quite similar to findings of previously conducted studies in Inkhorramabad (west Iran) [12], in Kuwait [16] and Kenya [17].

When we see a trend of $H$. pylori infection the prevalence was $86.5 \%$, in 2009 and it showed decrement to $51.8 \%$ in 2010. But the seroprevalence resume increasing to $61.3 \%$ in 2011 . Even though it previously showed some improvements still the seroprevalence is increasing which alarms for designing appropriate prevention and control strategies.

One limitation of our study was we had taken data only from three consecutive years which might reflect the trend of the seroprevalence in a limited way. We couldn't get data of the year of 2008 and beyond that and this makes us to see the trend of only the three consecutive years.

\section{Conclusion}

This study showed a seroprevalence of $65.7 \%$ among the dyspeptic patients in GUH which could be considered a high prevalence. The trend of the seroprevalence was varied from year to year in the three consecutive years. However it is showed that the seroprevalence has started increasing. Further studies in the community which are based on different diagnostic methods such as rapid urase, culture and histological test should be conducted so that the actual situation of $H$. pylori in general population can be known. In addition to this, further epidemiological investigation should be performed in order to determine the source, mode of transmition and the risk factors that might contribute for transmission of the pathogen.

\section{Abbreviation}

GUH: Gondar University Hospital.

\section{Competing interests}

The authors declare that they have no competing interests.

\section{Authors' contributions}

BM: initiation of the study, design, implementation, analysis and write-up. BM: design, implementation, analysis and write-up. MD: implementation, analysis and write-up. All authors read and approved the final manuscript.

\section{Acknowledgements}

We would like to thank the staffs of Gondar University Hospital Laboratory at large and Serology laboratory in particular for their unreserved cooperation during data collection.

\section{Author details}

${ }^{1}$ Department of Immunology and Molecular Biology, School of Biomedical and Laboratory Sciences, College of Medicine and Health Sciences, University of Gondar, Gondar, Ethiopia. ${ }^{2}$ Department of Medical Microbiology, School of Biomedical and Laboratory Sciences, College of Medicine and Health

Sciences, University of Gondar, Gondar, Ethiopia. 


\section{References}

1. Mégraud F: Epidemiology of Helicobacter pylori infection. Gastroenterol Clin North Am 1993, 22:73-88.

2. Goodwin CS, Armstrong J, Chilvers T, Peters M, Collins MD, Sly L, MCConnell W, Harper WES: Transfer of Campylobacter pylori and Campylobacter mustelae to Helicobacter gen. nov. as Helicobacter pylori comb. nov. and Helicobacter Mustelae comb. Nov., respectively. Int J Syst Bacteriol 1989, 39:397-405

3. Blaser MJ: Ecology of Helicobacter pylori in the human stomach. $J$ Clin Invest 1997, 100:759-762

4. Hussain S: H. pylori. "A multifacet evil". Pak J Gastroenterol 1989, 9(2):Editorial.

5. International Agency for Research on Cancer: Infection with Helicobactor pylori. IARC Monogr Eval Carcinog Risks Hum 1994, 61:177-240.

6. Peter S, Beglinger C: Helicobacter pylori and gastric cancer: the causal relationship. Digestion 2007, 75:25-35.

7. The EUROGAST Study Group: Epidemiology of, and risk factors for, Helicobacter pylori infection among 3194 asymptomatic subjects in 17 populations. Gut 1993, 34:1672-1676.

8. Feleke M, Afework K, Getahun M: Seroprevalence of H. pylori in dyspeptic patients and its relationship with HIV infection, $\mathrm{ABO}$ blood groupings and life style in GUH. World J Gastroenol 2006, 12:1957-1961.

9. Tadege T, Mengistu Y, Desta K, Asrat D: Seroprevalence of Helicobacter pylori infection in and its relationship with $\mathrm{ABO}$ Blood groups. Ethiop J Health Dev 2005, 19:55-59.

10. Desta K, Asrat D, Derbie F: Seroprevalence of helicobactor pylori infection among health blood donors in Addis Ababa. Ethiop Can J Gastroenterol 2007, 21:501-506.

11. Desta Z, Abula T, Gebre-Yohannes A, Worku A: Drug prescribing patterns for out patients in three hospitals in northwest Ethiopia. Ethiop J Health Dev 2002, 16:183-189.

12. Sheikhian A, Ataherian S, Delfan M, Ebrahimzadeh F, Pournia Y: Prevalence and risk factor analysis of $\mathrm{H}$. pylori health center referrals in Khorramabad (West Iran). Asian J Epidemiol 2011, 4:1-8.

13. Xia B, Xia HHX, Ma CW, Wong KW, Fung FMY, Hui CK, Chan CK, Chan AOO, Lai KC, Yuen MF, Wong BCY: Trends in the prevalence of peptic ulcer disease and $H$. pylori infection in Hong Kong. Aliment Pharmacol Ther 2005, 22:243-249.

14. Jackman RP, Schlinchting C, Carr W, Dubois A: Prevalence of Helicobacter pylori in United States navy submarine crews. Epidemiol Infect 2006, 134:460-464.

15. Naja F, Kreiger N, Sullivan T: Helicobacter pylori infection in Ontario: prevalence and risk factors. Can J Gastroenterol 2007, 21:501-506.

16. Alazmi WM, lqbal S, Nabeel A, Basil A-N: Prevalence of Helicobacter pylori infection among new outpatients with dyspepsia in Kuwait. BMC Gastroenterol 2010, 10:14.

17. Haim S, Samson O, Passaro DJ, Galia A, Jacob Y, Gerald F, Silvio P, Yaron N: Dyspepsia symptoms and Helicobacter pylori infection, Nakuru, Kenya. Emerg Infect Dis 2003, 9:1103-1107.

\section{doi:10.1186/1756-0500-6-346}

Cite this article as: Mathewos et al:: Seroprevalence and trend of Helicobacter pylori infection in Gondar University Hospital among dyspeptic patients, Gondar, North West Ethiopia. BMC Research Notes 2013 6:346.

\section{Submit your next manuscript to BioMed Central and take full advantage of:}

- Convenient online submission

- Thorough peer review

- No space constraints or color figure charges

- Immediate publication on acceptance

- Inclusion in PubMed, CAS, Scopus and Google Scholar

- Research which is freely available for redistribution 